\title{
BIOCHEMICAL STUDIES OF VIRUS-INFECTED CELLS*
}

\author{
W. Wilbur Ackermann \\ Department of Epidemiology and Virus Laboratory, \\ University of Michigan, Ann Arbor, Mich.
}

The orientation imposed by the subject of this monograph leads us to emphasize those aspects of the chemistry of infection that may serve our understanding of the morphology of infection. Indeed, much of the effort expended in this field has been justified under a hypothesis that the genesis of the cytopathic effect is a biochemical lesion. How that lesion is inflicted by the virus, the ensuing chain of secondary reactions, and the translation of molecular alterations to macrochanges, together, comprise the scope of our interest. Other papers in this monograph, while representing impressive advances, also express pre-eminently how incompletely the metabolic and morphologic effects of any viral infection can be described. Despite this, it may be well to sketch, in general terms, the over-all pattern as it appears in the light of present observations. In assuming the task, it is realized that the inevitable reward for any error proved upon me can only be the further advancement of virology.

A profitable consideration of the chemistry of viral infection as distinct from the chemistry of the virus has waited upon developments in tissue culture that allow, first of all, the important separation of the primary cytopathology from the inflammatory and proliferative effects of a secondary nature. An equally important result of the tissue culture technique is the ability to observe changes most easily by comparison of infected and normal cultures where, because of the completeness of infection, one is really comparing normal and infected cells. Only preliminary studies of the rate and nature of the initiation of infection allow one to proceed with assurance in this regard.

A variety of techniques is available to limit the infection in a particular culture to a single sequence. This is an essential for the correlation of viral synthesis with the observed cellular changes and for the determination of the natural order of these processes. If classic methods of biochemistry are to be employed, the use of mass cultures becomes mandatory and of greater value where infection is initiated synchronously in all cells, since this provides for interpretation at the cellular level. The few results already available emphasize the value of complete time studies during the infectious cycle if we are to have confidence that important observations are not overlooked.

Thus, with present techniques it is possible to direct our observations to very uniform multicellular cultures in which nearly every cell is undergoing a single cycle of infection in an almost synchronous manner. However, what is desired are cultures in which all cells during their growth cycle are performing physiological and biochemical activities synchronously.

Also prerequisite to a determination of effects whose cause is viral is a clear notion of the properties of the normal cell; these properties must be definable and measurable.

Inductive or stimulatory effects are best considered in resting cell systems

* The work reported in this paper was supported in part by a grant from The National Foundation, New York, N. Y. 
wherein activities are only potentials and in which the environment is competent for the realization of the potentials. Success in provoking a particular activity by virus or any other instrument establishes the competency of environment for this activity; failure only leaves the question unanswered.

Inhibitory or blocking effects of virus, in contrast, are best studied with cells in a dynamic state where the activities in question are proceeding. Properties of cells manifest only in the dynamic state are elegantly followed in synchronized cultures or in single cells.

Observations that fall in the first category of stimulatory or inductive effects will be considered first. Many of the findings presented elsewhere in this monograph are appropriate here and could serve as examples. However, because I have greater familiarity with the details of the studies reported by H. F. Maassab, I shall emphasize these preferentially.

Maassab reported that the composition of his control cultures during the experimental period remained constant when considered on a cellular basis. Constant composition would result if a static situation existed in which no net synthesis of ribonucleic acid (RNA) or desoxyribonucleic acid (DNA) was occurring, or equally as well if synthesis was proceeding rapidly in cells also undergoing completely asynchronous division.

Careful study of cellular division in cultures of ordinary HeLa cells sustained in 90 per cent maintenance solution (Scherer, 1953) and 10 per cent equine serum indicates that the former situation prevails. In the maintenance medium, cellular increase does not occur; net synthesis of cytoplasmic RNA, nuclear RNA, and DNA does not proceed at detectable levels, although these components may be metabolically active, as indicated by the considerable radioactive phosphate that they incorporate. The cells, of course, are utilizing glucose, consuming oxygen, and producing acid. Upon replacement of the maintenance medium with 90 per cent Eagle's medium (Eagle, 1955) and 10 per cent equine serum, cellular division resumes; the cells grow and increase in number. At present it has not been determined whether the maintenance medium either is simply deficient or is inhibitory; however, in either case, the effects are multiple, although possibly secondary to a primary or singular defect.

When such cultures of resting cells, sustained in maintenance medium, are infected with poliovirus, as Maassab has described, copious quantities of RNA and protein accumulate in the cytoplasm. It follows, therefore, that in the system precursors of RNA and protein and an appropriate source of energy are available. In the resting cell these syntheses are potential, the environment is competent for realization, and realization is attainable by virus action.

In the absence of virus, syntheses of these materials are disallowed by virtue of obligate linkages, with those reactions influenced primarily and adversely by the medium. It would appear that when conditions of environment that the cell might meet in the course of its natural history are unsuitable for the complete cycle of growth, limited development out of phase does not occur.

Since the virus infection did not stimulate a net synthesis of DNA or nuclear RNA, it is not possible to decide whether the maintenance medium is compatible with these reactions or not. Conclusions cannot be drawn as to whether the virus, on infecting the cell, is able to stimulate these syntheses or even if it 
can inhibit them. The competence of the environment for DNA synthesis might be established by infecting the cell with some other virus (Newton and Stoker, 1958) or the question might be examined experimentally with cells in a growth medium. As yet, these experiments have not been completed. It should be emphasized, however, that there are distinct early metabolic, as well as morphologic, effects demonstrable in the nucleus of infected cells.

So much for the basic description of the normal resting cell and its potential activities. The next consideration is one of the viral effect that has been described: the hyperdevelopment of cytoplasmic elements (Maassab et al., 1957; Loh et al., 1958).

The synthetic activity induced in the resting cell by the infection may not exceed that of the ordinary cell during the growth phase, particularly if we consider that the RNA and DNA of the daughter cell probably are formed only during a portion of the interphase and that the total generation time is only eighteen hours. One need not assume that the virus increases the basic potential of the cell.

The effect here of virus is conceived most simply (and this is speculation) as an uncoupling or disengaging action that releases the cytoplasmic reactions from obligate cross-linkages with other major synthetic activities with which they are normally coordinated.

The constant quality of cells through succeeding generations suggests the operation, during cellular development, of a mechanism that provides for the synthesis of various species of nucleic acids in fixed proportions. Thus, the synthesis of one species of RNA could not proceed independently of others. When conditions in a particular locus of the cell are suitable for RNA synthesis, all templates in the area function and, possibly by simple competition, duplicate in fixed proportions.

Again, it is economical to propose that this normal coordinating principle operates after infection and that replication of the viral-specific species of RNA triggers the development of other templates of RNA already present in the host cell.

It is obvious that we do not understand the principle underlying the coordinated synthesis of the various RNA molecules in the ordinary cell and much less how the virus may participate under such a principle. One clue may be the fact that the infectious cycle can be initiated by the isolated RNA of the poliovirus. If we restrict our thinking to the nucleic acid, it is tempting to propose that in the ordinary cell nucleic-acid synthesis occurs only at those times when the nucleic acid is freed from the nucleoprotein. Perhaps the simple presence of an active or free nucleic acid molecule in the metabolic milieu is sufficient to catalyze the dissociation of the resident nucleoproteins. In one sense the action of the virus would be to condition certain areas of the cell to synthetic activity and, when this has occurred, all templates would compete for available energy and precursors. Such hypotheses, so far removed from observation, have their chief value in suggesting experiments. From this hypothesis one would predict, as a result of infection, the production of much material that was not virus and not destined to be virus, but rather of a cellular type.

It is quite clear from experimental evidence (the quantities of materials involved, their distribution among the subcellular components, and the base 
composition of the RNA) that much material formed during poliovirus infection is indeed not of the viral type (Maassab et al., 1957; Loh et al., 1958). On the basis of quantitative considerations alone, it would appear that similar results obtain from infection with herpes virus (Newton and Stoker, 1958) and with adenovirus (Boyer et al., 1957). The second point, regarding the cellular nature of the newly formed material, awaits further investigation. However, in the case for poliovirus, the recent report of elevated levels of six glycolytic enzymes following infection (Matzelt et al., 1958) is of particular interest when we consider that normally they are found in the soluble fraction of the cytoplasm. This corresponds to fraction III, which we have found to increase in total protein content (Loh et al., 1958).

At this point we should not fail to recall that well-authenticated examples can be cited also in which there is the induction of synthesis of materials characteristic of infection, but of neither viral nor cellular nature. I refer to the proteins comprising the crystalline matrix found in cells of insects with polyhedral diseases (Bergold, 1953), the hemagglutinating protein of vaccinia infection (Chu, 1948), and the nonviral antigens found after phage infection of Escherichia coli (Watanabe, 1957). For these one would like to reserve some special functions in the viral developmental process. These may be of structural or, as with the $T_{2}$ bacteriophages, of metabolic significance (Flaks and Cohen, 1957).

A third class of materials, not to be ignored in preparing a balance sheet for infected cells, is that comprised by products resembling virus, but lacking full biological activity. This includes all the well-established soluble antigens and so-called incomplete virus forms. These are of such extensive and diverse natures that it would not serve our purpose to review them here.

It suffices to say that with poliovirus infection and, possibly, with the others cited, the first class of newly formed materials is quantitatively of the greatest significance and accounts for much of the histochemical visualization.

The central problem is: What is the biochemical basis of the cytopathogenic effect; how can any of the considerations just outlined be related to the central problem?

From a teleological viewpoint, there would seem to be value in the suppression of limited phases of cellular development under conditions restricting the full developmental cycle. Occasionally it has been observed that when extreme or abnormal conditions are imposed upon a cell and injury is very specific, partial development continues, usually with disastrous effects to the cell.

With the HeLa cell two examples may be cited: the action of $\mathrm{X}$ irradiation and the effect of fluorouracil. When cells are allowed to grow in the presence of this compound, many activities of the cells continue; the cells increase in size, but do not divide. The loss of viability proceeds, in time, to morphologic disintegration. The effect in growing medium can be prevented by the simultaneous addition of thymine and certain of its metabolic derivatives. However, once unbalanced development has occurred in the presence of inhibitor, viability cannot be restored upon the addition of thymine; the change is irreversible then (Ackermann et al., 1958b). Analogous situations have been described for thymidineless mutants of bacteria (Cohen and Barner, 1954).

From this line of reasoning, the difficulty arises when the normal activity 
stimulated by the virus is out of phase with other normal activities of the cell. The cytopathogenic effect might have its primary basis, not in the synthesis of a small amount of foreign material, but in an unbalanced growth of the cell. However, the final loss of morphologic integrity may result from the secondary accumulation of some particular substance. Such a cytotoxic substance has been described in a preliminary publication (Ackermann el al., 1958a).

Few ideas are truly new; the concept that growth stimulation is primary to necrosis has been suggested before on purely morphologic evidence (Rivers, 1928). In fact, some classifications of virus based upon pathology suggest a spectrum of agents: those causing neoplasms, those producing hyperplasia and necrosis, and finally, agents with pronounced necrotic effects.

The idea that the action of virus is fundamentally a stimulatory one would not be questioned in the case of carcinogenic viruses. Of interest in this connection is the recent report that, under different environmental circumstances, the polyoma virus may produce either necrotic or proliferative cytopathogenic effects (Eddy et al., 1958). Likewise, the late Duran-Reynals (1940) was much occupied with this dual nature of viruses. It might be proposed that all viruses possess this fundamental capacity to uncouple limited metabolic and structural areas of cells; different viruses, for example, those containing RNA or DNA, would affect different loci. The carcinogenic viruses would stimulate such wide areas that the cell may survive, although considerably altered.

\section{References}

Ackermann, W. W., F. E. Payne \& H. Kurtz. 1958a. Concerning the cytopathogenic effect of poliovirus; evidence for an extraviral toxin. J. Immunol. 81: 1.

Ackermann, W. W., P. C. LoH \& F. E. Payne. 1958b. Effects of 5-fluorouracil upon nucleic acid synthesis of ordinary and viral infected HeLa cells. Bacteriol. Proc. : 71.

BERGOLD, G. H. 1953, Insect viruses. Advances in Virus Research. 1: 91.

Boyer, G. S., C. Leuchtenberger \& H. S. Ginsberg. 1957. Cytological and cytochemical studies of HeLa cells infected with adenoviruses. J. Exptl. Med. 105: 195.

( $\mathrm{HU}, \mathrm{C} . \mathrm{M}$. 1948. Studies on vaccinia haemagglutinin. I. Some physicochemical properties. II. Some immunological properties. J. Hyg. 46: 42 .

CohEn, S. S. \& H. D. BARNER. 1954. Studies on unbalanced growth in Escherichia coli. Proc. Natl. Acad. Sci. U. S. 40: 885 .

Duran-Reynals, F, 1940. A hemorrhagic disease occurring in chicks inoculated with Rous and Fuginami viruses. Yale J. Biol. and Med. 13: 77.

EAGLE, H. 1955. The specific amino acid requirements of a human carcinoma cell (strain HeLa) in tissue culture. J. Exptl. Med. 102: 37.

EDdy, B. E., S. E. STEWART \& W. BERKELEY. 1958. Cytopathogenicity in tissue culture by a tumor virus of mice. Proc. Soc. Exptl. Biol. Med. 98: 848 .

Flaks, J. G. \& S. S. Conen. 1957. The enzymic synthesis of 5-hydroxymethyl-deoxycytidylic acid. Biochim. et Biophys. Acta. 25: 667 .

MaAssab, H. F., P. C. LoH \& W. W. AckermanN. 1957. Growth characteristics of poliovirus in HeLa cells: nucleic acid metabolism. J. Exptl. Med. 106: 641.

Matzelt, D., J. Homman \& H. Lennartz. 1958. Das Verhalten glykolytischer Enzymaktivitäten in Gewebekulturen vor und nach Beimfund mit Virus. II. Messungen an Gewebekulturen, die mit Poliomyelitisvirus, Type I, infiziert würden im Vergleich zu "normalen" Gewebekulturen. Biochem. Z. 330: 260.

Newton, A. \& M. G. Stoker. 1958. Changes in nucleic acid content of HeLa cells infected with herpes virus. Virology. 5: 549.

Loh, P. C., F. E. PAYNe, \& W. W. ACKERMANn. 1958. Synthesis of ribonucleic acid in HeLa cells infected with poliovirus. Federation Proc. 17: 524.

Rivers, T. M. 1928. Some general aspects of pathological conditions caused by filterable viruses. Am. J. Pathol. 4: 91.

Scherer, W. F. 1953. The utilization of a pure strain of mammalian cells (Earle) for the cultivation of viruses in vitro. I. Am. J. Pathol. 29: 113.

Watanabe, E. 1957. Formation of non-phage-antigenic protein in $E$. coli infected with $T_{2}$ phage. Biochim. et Biophys. Acta. 25: 665 . 